\title{
Precision and Safety of an Intravascular Temperature Management System for Postcardiac Arrest Syndrome Patients: A Multicenter Clinical Trial (COOL-ARREST JP)
}

\author{
Tsuyoshi Maekawa, MD, PhD, ${ }^{1}$ Kotaro Kaneda, MD, PhD, ${ }^{2}$ Ryosuke Tsuruta, MD, PhD, ${ }^{2}$ \\ Yasuhiro Kuroda, MD, PhD, ${ }^{3}$ Ken Nagao, MD, PhD, ${ }^{4}$ Hiroshi Rinka, MD, PhD, ${ }^{5}$ \\ Takeshi Takahashi, MD, PhD, ${ }^{6}$ Hiroyuki Yokota, MD, PhD, ${ }^{7}$ Shin-Ichi Shirai, MD, PhD, \\ Mamoru Hase, MD, PhD, ${ }^{9}$ Joji Kotani, MD, PhD, ${ }^{10}$ and Shigeatsu Endo, MD, PhD ${ }^{11}$; \\ on behalf of the COOL-ARREST JP Investigators*
}

Rapid induction and maintaining a target temperature of $32.0-36.0^{\circ} \mathrm{C}$ within a narrow range for $<24$ hours are essential, but those are very hard to perform in postcardiac arrest syndrome (PCAS) patients. We investigated the usability of an intravascular temperature management (IVTM) system with neurolept-anesthesia (NLA; droperidol and fentanyl). Single-arm, prospective multicenter trial was carried out in the seven university and the three affiliated hospitals. In the 24 comatose PCAS patients, the target temperature $\left(33.0^{\circ} \mathrm{C}\right)$ was rapidly induced and maintained for 24 hours using an IVTM system with NLA. The rewarming speed was $0.1^{\circ} \mathrm{C} / \mathrm{h}$ until $36.5^{\circ} \mathrm{C}$ and was maintained for 24 hours. The primary end point was the ability to achieve $\leq 34.0^{\circ} \mathrm{C}$ for $<3$ hours after starting cooling, and the secondary end points were the cooling rate, deviation from the target temperature, and adverse events. Cerebral Performance Category (CPC) score at 14 days was also evaluated. Statistical analyses were performed by SPSS software, using the intention-to-treat data sets. The target temperature of $\leq 34.0^{\circ} \mathrm{C}$ was reached by 45 minutes (35-73 minutes) and was within 3 hours in all patients. The cooling rate from $36.4^{\circ} \mathrm{C}$ to $33.0^{\circ} \mathrm{C}$ was $2.7^{\circ} \mathrm{C} / \mathrm{h}\left(2.4-3.6^{\circ} \mathrm{C} / \mathrm{h}\right)$. The temperature of $33.1^{\circ} \mathrm{C}\left(33.1-33.1^{\circ} \mathrm{C}\right)$ and $36.7^{\circ} \mathrm{C}\left(36.6-36.9^{\circ} \mathrm{C}\right)$ for 24 hours each was held during the maintenance and the after rewarming phases, respectively. Temperature deviations $>0.2^{\circ} \mathrm{C}$ from $33.0^{\circ} \mathrm{C}$ in the maintenance phase occurred once each in two patients. The favorable neurological outcomes $(\mathrm{CPC} 1,2)$ were relatively good $(50 \%)$. Five patients experienced serious adverse events; none was device related. We rapidly achieved therapeutic hypothermia within a narrow temperature range without major complications using the IVTM system with NLA in PCAS patients.

Keywords: therapeutic hypothermia, intravascular cooling, neurolept-anesthesia, postcardiac arrest syndrome, cooling speed, cerebral performance category, prospective multicenter trial

\footnotetext{
${ }^{1}$ Yamaguchi Prefectural University, Yamaguchi, Japan.

${ }^{2}$ Advanced Medical Emergency and Critical Care Medicine, Yamaguchi University Hospital, Yamaguchi, Japan.

${ }^{3}$ Emergency Medical Center, Kagawa University Hospital, Miki, Japan.

${ }^{4}$ Cardiovascular Disease Center, Nihon University Hospital (Surugadai), Nihon University Hospital, Tokyo, Japan.

${ }^{5}$ Emergency and Critical Medical Care Center, Osaka City General Hospital, Osaka, Japan.

${ }^{6}$ Kumamoto Medical Center, Kumamoto, Japan.

${ }^{7}$ Emergency and Critical Care Medicine, Nippon Medical School Hospital, Tokyo, Japan.

${ }^{8}$ Cardio-Vascular Center, Kokura Memorial Hospital, Fukuoka, Japan.

${ }^{9}$ Department of Traumatology and Critical Care Medicine, Sapporo Medical University Hospital, Sapporo, Japan.

${ }^{10}$ Center for Emergency and Critical Care Medicine, Kobe University Hospital, Kobe University Hospital, Kobe, Japan.

${ }^{11}$ Advanced Emergency and Critical Care Center, Iwate Medical University Hospital, Morioka, Japan.

Prior presentation: Results of this study were presented at the 46th Critical Care Congress of the Society of Critical Care Medicine, January 21-25, 2017, Honolulu, Hawaii, USA.

*For members see the Authors' Information section.

(C) Tsuyoshi Maekawa et al., 2020; Published by Mary Ann Liebert, Inc. This Open Access article is distributed under the terms of the Creative Commons License (http://creativecommons.org/licenses/by/4.0), which permits unrestricted use, distribution, and reproduction in any medium, provided the original work is properly cited.
} 


\section{Introduction}

$\mathbf{T}$ ARGETED TEMPERATURE MANAGEMENT or therapeutic hypothermia (TH) of $32.0-36.0^{\circ} \mathrm{C}$ is essential for postcardiac arrest syndrome (PCAS) patients to achieve favorable neurological outcomes (Bernard et al., 2002; The Hypothermia After Cardiac Arrest Study Group, 2002; Morrison and Deakin, 2010; Nielsen et al., 2013). There are many methods for TH. Hoedemaekers et al. (2007) compared the five methods and determined that an intravascular cooling system achieved the greatest cooling speed and the smallest deviation. There is a clear clinical need to introduce a cooling method capable of cooling patients more rapidly and maintaining the target temperature more tightly than existing methods.

In this study, we evaluated the safety and effective use of an intravascular temperature management (IVTM) system together with an appropriate anesthetic method in PCAS patients.

\section{Materials and Methods}

\section{Study population}

We conducted a nonblinded, single-arm, prospective multicenter (10 hospitals) clinical trial in Japan between May 2013 and January 2014. The protocol was approved by the Institutional Review Boards at all participating hospitals, and the trial was registered on the U.S. National Institute of Health ClinicalTrials.gov website (identifier: NCT01847482). The trial was overseen by an independent data safety monitoring board.

The inclusion criteria were in-hospital or out-of-hospital cardiac arrest with ventricular tachycardia/fibrillation (VT/VF) or witnessed cardiac arrest with pulseless electrical activity/asystole within 15 minutes of onset; inability to follow verbal instructions; age 20-80 years; and the ability to begin cooling $<6$ hours after return of spontaneous circulation (ROSC).

Exclusion criteria were traumatic cardiac arrest; patient temperature $<35.0^{\circ} \mathrm{C}$ upon admission; pregnancy; terminal disease; severe hemorrhage; unstable arterial blood pressure with catecholamine support; hypersensitivity to heparin; systemic infection or sepsis/septic shock; thrombocyte count $<30,000 / \mathrm{mm}^{3}$; severe hepatic, renal, or cardiac failure; contraindication for femoral vein access; using percutaneous cardiopulmonary support; continuous hemodiafiltration; or if the physician determined the patient to be ineligible for the study. Eligible patients were registered in the study after we obtained informed consent from the next of kin.

\section{Anesthesia and muscle relaxant}

Neurolept-anesthesia (NLA) comprised droperidol [neuroleptic effect, initial: $0.5 \mathrm{mg} / \mathrm{kg}$, divided by $1 / 10-1 / 5$ doses with fluid loading to keep arterial pressure, because of its alpha 1 blocking effect; maintenance: $0.025 \mathrm{mg} /(\mathrm{kg} \cdot \mathrm{h})]$ and fentanyl [narcotic and analgesic effects, initial: $0.01 \mathrm{mg} / \mathrm{kg}$; maintenance: $1.0 \mu \mathrm{g} /(\mathrm{kg} \cdot \mathrm{h})$ ] (Atkinson et al., 1977; Maekawa et al., 2015). Supplemental midazolam was used, when the physician decided to need the patients unconscious in the present study. During the induction and the maintenance phases, patients were intravenously administered a muscle relaxant, either pancuronium or vecuronium $[0.10 \mathrm{mg} / \mathrm{kg}$, $0.05 \mathrm{mg} /(\mathrm{kg} \cdot \mathrm{h})]$. During the rewarming and the normal temperature maintaining phases, patients were administered the same muscle relaxant as deemed necessary.

\section{Study intervention}

Patients were intubated and manually or mechanically ventilated. Percutaneous coronary artery intervention was also performed if necessary. Up to $30 \mathrm{~mL} / \mathrm{kg}$ of cold $\left(4^{\circ} \mathrm{C}\right)$ dextrosefree crystalloid solution or plasma expander could be transfused until the start of the IVTM cooling system (Bernard et al., 2003; Kliegel et al., 2005). The IVTM system comprised a Thermogard XP ${ }^{\circledR}$ (TGXP) and Start-up Kit fitted with a Quattro ${ }^{\circledR}$ or an $\mathrm{ICY}^{\circledR}$ (4 or 3 balloons, used depending upon his/her high in 17 or 7 patients) intravascular heat exchange catheter (ZOLL Circulation, San Jose, CA) was used under NLA with neurooriented intensive care (Atkinson et al., 1977; Maekawa et al., 1997, 2015; Polderman and Herold, 2009). The intravascular heat exchange catheter was introduced into the inferior vena cava through a femoral vein using the Seldinger technique and was connected to the circuit. The tip of the catheter in his/her inferior vena cava was ensured by a simple X-ray film. Deep vein thrombosis in their inferior vena cava was evaluated by an echo angiography, a computed tomography, and/or blood examination (platelet count, fibrinogen, fibrinogen degeneration product, and D-dimer).

The primary site for temperature measurement was the middle of the esophagus, and the secondary site was the bladder. The probe and the circuit were connected to the TGXP, and the esophageal probe provided thermal feedback. Temperature was recorded at 1-minute intervals using the IVTM device and every 20 minutes manually. A total of $500 \mathrm{~mL}$ saline was circulated through the balloons. Patients were cooled as quick as possible to the target temperature of $33^{\circ} \mathrm{C}$ with a permitted range of $32.0-34.0^{\circ} \mathrm{C}$ for 24 hours during the maintenance phase, and body temperature was maintained at $36.5^{\circ} \mathrm{C}$ for 24 hours after the rewarming phase. The rewarming speed was controlled at $0.1^{\circ} \mathrm{C} / \mathrm{h}$.

\section{Evaluation}

The primary end point was the percentage of patients whose temperature reached $\leq 34.0^{\circ} \mathrm{C}$ within 3 hours using the IVTM cooling system. Secondary end points were as follows: deviation of body temperature from the target temperature $\left(33.0^{\circ} \mathrm{C}\right)$ during the use of the IVTM system; cooling rate (change in temperature per unit of time); and safety measures, which included adverse events, abnormal changes in laboratory test values, and IVTM system malfunctions during the study. The mean error was also calculated from the difference between the recorded temperature and the target temperatures to quantify temperature deviation (Matthews et al., 1990). Cerebral Performance Category (CPC) score was also evaluated 14 days after ROSC (Safar, 1981).

\section{Statistical analysis}

All data were analyzed descriptively using the intentionto-treat approach. Data are expressed as the median (interquartile range) for continuous variables or as the number of patients (percent) for categorical variables. All analyses were performed using SPSS software version 22.0 (IBM Corp., Armonk, NY). 


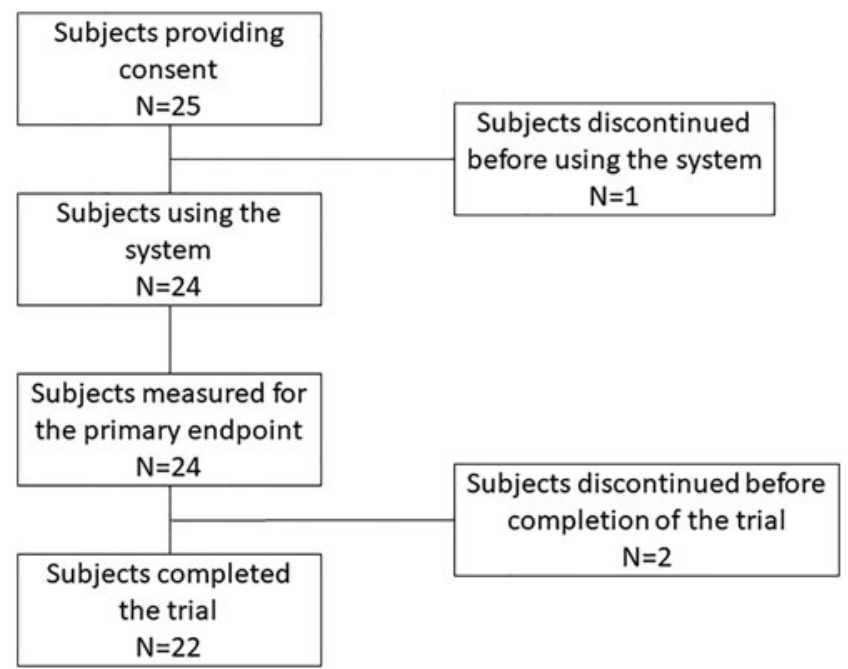

FIG. 1. Patient disposition.

\section{Results}

All of 25 comatose PCAS patients, who experienced out-ofhospital cardiac arrest, were initially enrolled (Fig. 1). Among 24 IVTM system used patients, 2 patients were withdrawn after the target temperature of $33^{\circ} \mathrm{C}$ was reached, because of the physicians' decision. The data obtained for these two patients during and after the maintenance phase were excluded from the analyses, except for their neurological outcomes. Patient characteristics, physiological variables, and laboratory data on admission or upon stabilization are shown in Table 1. The median volume of cold fluid transfusion until the start of the IVTM cooling system was $21 \mathrm{~mL} / \mathrm{kg}(14-27 \mathrm{~mL} / \mathrm{kg})$, and the core body temperature was $36.4^{\circ} \mathrm{C}\left(35.2-36.8^{\circ} \mathrm{C}\right)$ at that time. The time from ROSC to the start of cooling was 249 minutes (216-342 minutes) (Table 2). The time to reach the target temperature of $\leq 34.0^{\circ} \mathrm{C}$ was 45 minutes (35-73 minutes) (Table 3). The longest time was 180 minutes, so the primary end point was achieved in all 24 patients. The cooling rate during the induction phase was $2.7^{\circ} \mathrm{C} / \mathrm{h}\left(2.4-3.6^{\circ} \mathrm{C} / \mathrm{h}\right)$. The patient temperature was $33.1^{\circ} \mathrm{C}\left(33.1-33.1^{\circ} \mathrm{C}\right)$ at 8 and
24 hours during the maintenance phase, respectively. After rewarming (the target temperature: $36.5^{\circ} \mathrm{C}$ ), it was $36.6^{\circ} \mathrm{C}$ $\left(36.5-36.6^{\circ} \mathrm{C}\right)$ at 8 hours and $36.7^{\circ} \mathrm{C}\left(36.6-36.9^{\circ} \mathrm{C}\right)$ at 24 hours (Table 3). Manual temperature recordings at 20-minute intervals showed that the recorded temperature differed from the target temperature by $\geq 0.2^{\circ} \mathrm{C}$ in two patients, once in each patient, but there was no deviation of $\geq 0.5^{\circ} \mathrm{C}$ during the maintenance phase. Data recorded minute by minute were available for 19 patients (Fig. 2). Five patients were not included in this figure, because two patients were withdrawn, data of two other patients were incomplete, and data of the other patient were overwritten by data for the next patient. The Figure 2 confirms that the patients' temperature is tightly controlled by the IVTM system in each of the temperature management phases. The mean error was $0.09^{\circ} \mathrm{C}$ $\left(0.06-0.11^{\circ} \mathrm{C}\right)$ during the maintenance phase (targeted $\left.33.0^{\circ} \mathrm{C}\right)$ and $0.11^{\circ} \mathrm{C}\left(0.07-0.17^{\circ} \mathrm{C}\right)$ after rewarming (targeted $\left.36.5^{\circ} \mathrm{C}\right)$.

One IVTM system malfunctioned due to a leak in the Startup Kit line after the rewarming phase. The Start-up Kit line was exchanged, and the treatment was completed without harm to the patient. Serious adverse events occurred in five patients. Two patients were withdrawn from the study protocol during the maintenance phase due to recurrent $\mathrm{VF}$, which necessitated rewarming, as described above. The other patient had VF due to hypokalemia, but a normal rhythm was achieved using standard treatments. One patient had acute respiratory distress syndrome on 11th day after ROSC, and it was improved by ordinary treatments. There was a report of deep vein thrombosis around the IVTM heat exchange catheter in one patient and treated without any other complication.

CPC at 14 days were favorable, with CPC grades of 1,2, 3, 4, and 5 in $11,1,2,9$, and 1 patient in the present study, respectively, while those were in 2, $0,1,3$, and 0 in the pulseless electrical activity patients, respectively.

\section{Discussion}

In the present study, all of the patients were cooled quickly to $34.0^{\circ} \mathrm{C}$ within 3 hours, actually it was 45 minutes (35-73 minutes) after starting the cooling process, and the cooling rate from $36.4^{\circ} \mathrm{C}$ to $33.0^{\circ} \mathrm{C}$ was $2.7^{\circ} \mathrm{C} / \mathrm{h}\left(2.4-3.6^{\circ} \mathrm{C} / \mathrm{h}\right)$. The target core

Table 1. Patient Characteristics on Admission and Physiological and Laboratory Variables Following Stabilization

\begin{tabular}{|c|c|c|c|}
\hline \multicolumn{2}{|c|}{ Patient characteristics on admission } & \multicolumn{2}{|c|}{ Physiological and laboratory variables } \\
\hline Age (years) & $60(43-70)$ & Mean BP (mmHg) & $98(64-123)$ \\
\hline Male & $21(87.5 \%)$ & HR (bpm) & $110(74-123)$ \\
\hline Height $(\mathrm{cm})$ & $170(162-174)$ & $\mathrm{PaO}_{2}(\mathrm{mmHg})$ & $128(64-316)$ \\
\hline Weight (kg) & $70(60-75)$ & $\mathrm{PaCO}_{2}(\mathrm{mmHg})$ & $47.9(37.1-53.3)$ \\
\hline BMI $\left(\mathrm{kg} / \mathrm{m}^{2}\right)$ & $24.4(23.2-25.3)$ & $\mathrm{pH}$ & $7.25(7.18-7.30)$ \\
\hline $\operatorname{BSA}\left(\mathrm{m}^{2}\right)$ & $1.75(1.63-1.85)$ & $\mathrm{BE}(\mathrm{mEq} / \mathrm{L})$ & $-8.4(-11.5$ to -5.1$)$ \\
\hline \multicolumn{2}{|c|}{ Characteristics of cardiac arrest on admission } & Lactate $(\mathrm{mg} / \mathrm{dL})$ & $50.4(32.0-70.0)$ \\
\hline Out of hospital & $24(100 \%)$ & Glucose $(\mathrm{mg} / \mathrm{dL})$ & $244(200-323)$ \\
\hline Witnessed & $21(87.5 \%)$ & CRP (mg/dL) & $0.11(0.09-0.22)$ \\
\hline $\mathrm{VT} \cdot \mathrm{VF}$ & $18(75.0 \%)$ & GCS on admission & $3(3-6)$ \\
\hline PEA & $6(25.0 \%)$ & & \\
\hline
\end{tabular}

Values are expressed as the median (interquartile range) or $n(\%)$ for the intention to treat population $(n=24)$.

BE, base excess; BMI, body mass index; BSA, body surface area; BP, blood pressure; CRP, C-reactive protein; GCS, Glasgow coma scale score; $\mathrm{HR}$, heart rate; $\mathrm{PaCO}_{2}$, partial pressure of arterial carbon dioxide; $\mathrm{PaO}_{2}$, partial pressure of arterial oxygen; PEA, pulseless electrical activity; VF, ventricular fibrillation; VT, ventricular tachycardia. 
Table 2. Duration from Cardiac Arrest or Return of Spontaneous Circulation and Volume of Cold Fluid Transfusion Before the Start OF THE INTRAVASCULAR TEMPERATURE Management Cooling System

Clinical variables

Cardiac arrest to admission (minutes)

Cardiac arrest to ROSC (minutes)

Cardiac arrest to start cooling (minutes)

ROSC to start cooling (minutes)

Volume of cold fluid transfusion $(\mathrm{mL} / \mathrm{kg})^{\mathrm{a}}$

$\begin{aligned} 32 & (26-120) \\ 20 & (14-35) \\ 274 & (242-359) \\ 249 & (216-342) \\ 21 & (14-27)\end{aligned}$

Values are expressed as the median (interquartile range) for the intention-to-treat population $(n=24)$.

${ }^{\mathrm{a}}$ Cold fluid $\left(4^{\circ} \mathrm{C}\right.$, up to $30 \mathrm{~mL} / \mathrm{kg}$ body weight $)$ could be transfused until the start of the IVTM cooling system.

IVTM, intravascular temperature management; ROSC, return of spontaneous circulation.

body temperature $\left(33.0^{\circ} \mathrm{C}\right)$ was maintained within an extremely narrow range, and patients were rewarmed smoothly (Table 3 and Fig. 2). These results provide further evidence for the precision and usability of the IVTM system, combined with NLA and neuro-oriented intensive care (Atkinson et al., 1977; Maekawa et al., 1997, 2015; Polderman and Herold, 2009).

\section{Cooling speed and the rate to reach the targeted temperature}

The target temperature of $34^{\circ} \mathrm{C}$ was achieved in $260 \mathrm{~min}-$ utes, mainly using surface cooling by Nielsen et al. (2013), in

Table 3. Core Body Temperatures and Times to Reach TARget Temperatures

\begin{tabular}{|c|c|c|}
\hline $\begin{array}{l}\text { Timing of core body } \\
\text { temperature record }\end{array}$ & $\begin{array}{l}\text { Patient } \\
\text { number }\end{array}$ & ${ }^{\circ} \mathrm{C}$ \\
\hline At registration & 24 & $36.1(35.6-37.0)$ \\
\hline Just before cooling & 24 & $36.4(35.2-36.8)$ \\
\hline $\begin{array}{l}\text { Start of the maintenance } \\
\text { phase }\end{array}$ & 24 & $34.0(33.9-34.0)$ \\
\hline $\begin{array}{l}8 \text { Hours after reaching } \\
\text { the target temperature }\end{array}$ & 22 & $33.1(33.1-33.1)$ \\
\hline $\begin{array}{l}24 \text { Hours after reaching } \\
\text { the target temperature }\end{array}$ & 22 & $33.1(33.1-33.1)$ \\
\hline $\begin{array}{l}\text { At the time of reaching } \\
\text { the normal temperature }\end{array}$ & 22 & $36.0(36.0-36.0)$ \\
\hline $\begin{array}{l}8 \text { Hours after reaching } \\
\text { the normal temperature }\end{array}$ & 22 & $36.6(36.5-36.6)$ \\
\hline $\begin{array}{l}24 \text { Hours after reaching } \\
\text { the normal temperature }\end{array}$ & 22 & 36.7 (36.6-36.9) \\
\hline $\begin{array}{l}\text { Times to reach target } \\
\text { temperatures }\end{array}$ & $\begin{array}{l}\text { Patient } \\
\text { number }\end{array}$ & $\begin{array}{l}\text { Minutes } \\
\text { or }{ }^{\circ} \mathrm{C} / \mathrm{h}\end{array}$ \\
\hline $\begin{array}{c}\text { Time from starting cooling } \\
\text { to reach } 34^{\circ} \mathrm{C} \text { (minutes) }\end{array}$ & 24 & $45(35-73)$ \\
\hline $\begin{array}{l}\text { Rate of cooling to reach } \\
33^{\circ} \mathrm{C}\left({ }^{\circ} \mathrm{C} / \mathrm{h}\right)\end{array}$ & 24 & $2.7(2.4-3.6)$ \\
\hline
\end{tabular}

Values are expressed as the median (interquartile range).

The values for two patients were excluded after the target temperature of $33^{\circ} \mathrm{C}$ was reached, because the physicians decided that the patients' conditions were too poor to continue therapeutic hypothermia.
188 and 170 minutes using an IVTM system and ordinary surface cooling by Tømte et al. (2011), and in 330 minutes using an IVTM system with a two balloon catheter by Deye et al. (2015). The target temperature of $33^{\circ} \mathrm{C}$ was achieved in 190 minutes by Keller et al. (2003), in 210 minutes using an IVTM system with a two balloon catheter by Al-Senani et al. (2004), in 179 or 208 minutes using an IVTM system (62\% of patients) by Kirkegaard et al. (2017), and in 89 minutes (42155 minutes) using the same IVTM system (Thermogard XP) with a three or four balloon catheter by Sawyer et al. (2019). Concerning about the cooling rate to reach $33.0^{\circ} \mathrm{C}$, it was $0.8^{\circ} \mathrm{C} / \mathrm{h}$, achieved by Al-Senani et al. (2004), and $0.39^{\circ} \mathrm{C} / \mathrm{h}$ by Deye et al. (2015), respectively. All these reports took much longer duration and much slower cooling rates than those of ours (Table 3 and Fig. 2). Possible reasons might be their cooling methods; they used surface cooling and/or the endovascular cooling system with a two-balloon catheter, except for Sawyer's trial (2019), while we used an IVTM system with a three or four balloon catheter.

When the patients were limited to the VT/VF, Schock et al. (2018) reviewed the report of Howes et al. (2010), and rapid cooling to $34.0^{\circ} \mathrm{C}$ within 3.5 hours of ROSC and cooling rate $>3.0^{\circ} \mathrm{C} / \mathrm{h}$ without cold fluid volume load yielded a higher rate of good neurological outcome (around 80\%). We calculated the duration from ROSC to $34.0^{\circ} \mathrm{C}$ in the VT/VF patients $(n=18)$. It was 5.4 hours, and the good neurological outcome $(\mathrm{CPC} 1+2)$ was $55.6 \%$ with similar cooling speed, $3.0^{\circ} \mathrm{C} / \mathrm{h}$ to $34.0^{\circ} \mathrm{C}$ after the start of cooling. The difference of the neurological outcome would come from our delayed start of cooling.

Sakamoto et al. (2014) reported much quicker cooling methods, such as an extracorporeal cardiopulmonary support device, which were compared to conventional cooling methods and had better neurological outcome, $11.2 \%$ versus $1.5 \%$ at 6 months, respectively. Polderman et al. (2015) reported an ultrarapid induction method, an automated peritoneal lavage system using ice-cold fluids, and had much better neurological outcome as $56.4 \%$ at 6 months in VT/VF patients on arrival, although their methods were more invasive than our methods.

\section{Deviation from the targeted temperature}

Figure 2 shows the minute-by-minute recording of the core body temperature measured in the middle of esophagus for 19 patients. The mean error was $0.09^{\circ} \mathrm{C}\left(0.06-0.11^{\circ} \mathrm{C}\right)$ during the maintenance phase and $0.11^{\circ} \mathrm{C}\left(0.07-0.17^{\circ} \mathrm{C}\right)$ after the rewarming phase. Considering possible differences in calculations, we demonstrated better temperature management in the present study than was observed in prior studies. The precision and rapid cooling rate were due to direct intravascular blood cooling, in which cooled blood quickly and directly suppressed the function of the thermal control centers in the anterior hypothalamic-preoptic area and the posterior hypothalamus (Guyton and Hall, 2005). By contrast, body surface cooling constricts subcutaneous arteries and arterioles, which might disturb thermal exchange and stimulate the thermal control centers using cutaneous thermal receptors, ultimately triggering shivering (Guyton and Hall, 2005). These physiological responses may enormously influence the cooling speed and temperature precision. 


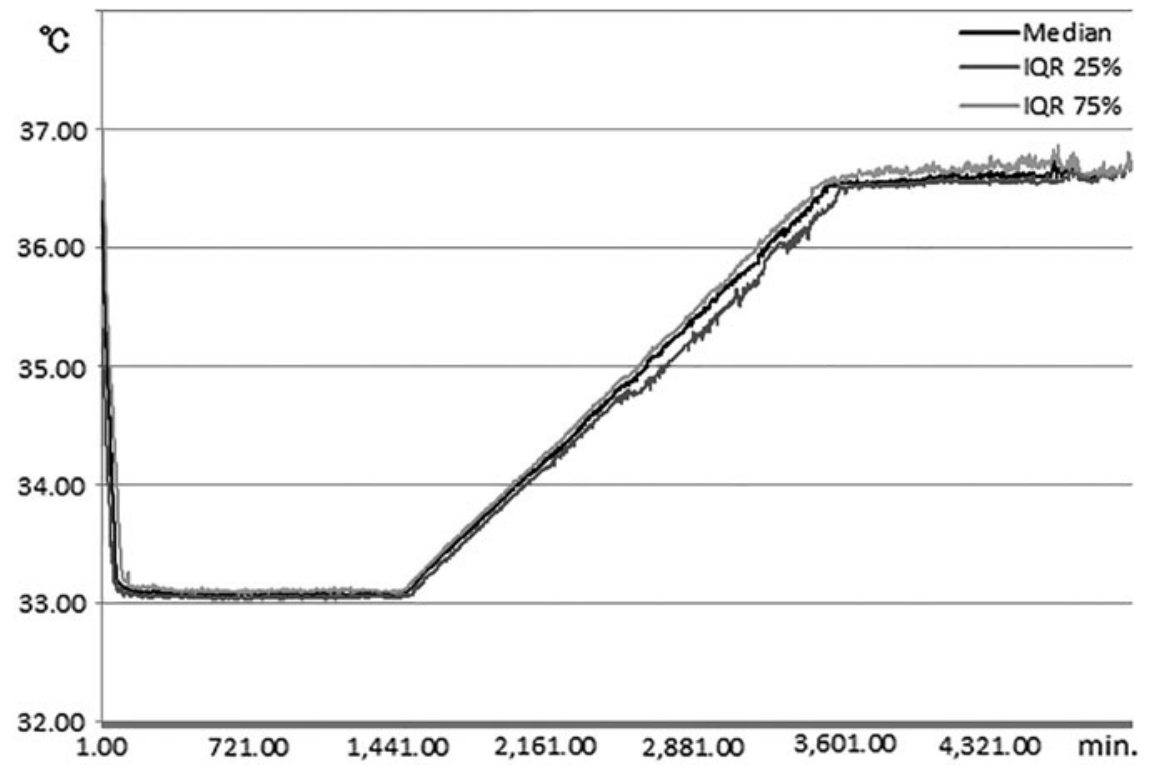

FIG. 2. Core body temperature measured every minute in 19 patients who completed the protocol and whose temperature was recorded on the device. The values are expressed as the median and interquartile range.

\section{Anesthesia and muscle relaxants}

TH itself might be seriously harmful stimuli, so that appropriate anesthesia or sedation with analgesics must be needed, as Canadian TH guideline strongly suggested (Howes et al., 2016). Propofol and midazolam are widely used as sedatives, and fentanyl or morphine is often used as analgesics (Chamorro et al., 2010). However, those sedatives decreased cerebral blood flow (Oshima et al., 2002; Kaisti et al., 2003; Ogawa et al., 2010; Reves et al., 2010), while NLA which was used in the present study did not decrease cerebral blood flow in humans (Sari et al., 1972; Patel and Drummond, 2010). Besides its sedative and amnesic effects, droperidol dilated peripheral arteries and arterioles by blocking alpha 1 adrenoceptors and improved peripheral circulation (Atkinson et al., 1977) and facilitated heat exchange throughout the body, while we administered dobutamine (beta agonist) to maintain cardiac output, MAP (60$150 \mathrm{mmHg}$ ), and cerebral blood flow, as deemed necessary. Narcotic properties of fentanyl partly suppressed shivering, suppressed endogenous catecholamine release, and prevented vasoconstriction (Fukuda, 2010).

Nondepolarizing muscle relaxants which we used completely block neuromuscular junctions, thus suppressing shivering and preventing an increase in body temperature (Naguib and Lien, 2010). In PCAS patients, Salciccioli et al. (2013) reported that continuous neuromuscular blockade improved the survival rate. Therefore, our methods of anesthesia and muscle relaxation would contribute good temperature management for PCAS patients.

\section{Neurological outcomes}

Overall, $12 / 24$ patients $(50 \%)$ had a favorable neurological outcome, 14 days after ROSC, even though TH had started relatively late, 249 minutes (216-342 minutes) after ROSC (Table 2). The reasons might be included, that is, the high rate of witnessed PCAS patients $(87.5 \%)$, the relatively short resuscitation period (20 and 14-35 minutes), the prevention of pyrexia by cold fluid transfusion, and tight management of the body temperature for $>72$ hours (Tables 2, 3, and Fig. 2).

\section{Limitation}

There are limitations of our clinical study. First, because it was a nonblinded, single-arm clinical trial, the results cannot be directly compared to those reported for other cooling methods. Second, this was a government-required clinical trial for regulatory approval of the IVTM system in Japan and, as such, it was financially and logistically supported by the manufacturer. Therefore, safety was the most important factor. In the future, it would be beneficial to perform multicenter randomized controlled clinical trials using the IVTM system with NLA to treat PCAS patients.

In conclusion, the IVTM cooling system with NLA successfully and rapidly induced $\mathrm{TH}$ with low deviation from the targeted temperature and without major complications in PCAS patients. The results indicate that the IVTM system is suitable for managing TH and rewarming in PCAS patients.

\section{Authors' Information}

COOL-ARREST JP Clinical Trial Group:

\section{Sapporo Medical University Hospital}

Chief Investigator: Mamoru Hase

Sub Investigator: Katsutoshi Tanno, Noriaki Kokubun,

Shuji Uemura, Junichi Nishida, Hisashi Fumiya, Eiji

Sakawaki

Iwate Medical University Hospital

Chief Investigator: Shigeatsu Endo

Sub Investigator: Katsutoshi Terui, Tomohiro Takahashi, Chikahiko Hida, Chiaki Onodera

\section{Nippon Medical School Hospital}

Chief Investigator: Hiroyuki Yokota

Sub Investigator: Akira Fuse, Tomohiko Masuno, Hideyoshi Onda, Hironori Ishii, Masato Miyauchi, Fumihide Kin, Atsuko Tsujii, Takeshi Suzuki, Masanori Arai, Jun Hagiwara, Takeshi Tsukamoto, Keiji Tanaka, Koichi Akutsu, Takeshi Yamamoto, Yusuke Hosokawa, Hiroshige Murata, Mitsunobu Kitamura, Hideki Miyaji, Hidekazu Kawanaka, Tetsuhiro Hashizume, Shoji Yokobori 
Osaka City General Hospital

Chief Investigator:Hiroshi Rinka

Sub Investigator: Isanori Miyaichi, Hideki Arimoto,

Akihiro Fuke, Junichi Ishikawa, Takaya Morooka, Daisuke

Arashi, Yuko Hamanaka, Ken Morimoto, Junpei Okawa,

Taneaki Shigemitsu

Kagawa University Hospital

Chief Investigator: Yasuhiro Kuroda

Sub Investigator: Kenya Kawakita, Yuko Abe, Natsuyo

Shinohara, Shuichi Okubo, Kazutaka Kiritsume, Hideyuki

Hamatani, Koshiro Takano

Yamaguchi University Hospital

Chief Investigator: Ryosuke Tsuruta

Sub Investigator: Kotaro Kaneda, Yasutaka Oda,

Yoshikatsu Kawamura, Motoki Fujita, Takashi Nakahara,

Yasutaka Koga, Yasuaki Ogino, Shinya Fukuda, Ichiko

Mizuguchi, Mari Otsuji, Takefumi Yagi, Takashi Miyauchi,

Ryo Tanaka, Masaki Toya, Tadashi Kaneko

Kokura Memorial Hospital

Chief Investigator: Masashi Iwabuchi, Kenji Ando

Sub Investigator: Shinichi Shirai, Junichi Shimotakahara,

National Hospital Organization, Kumamoto Medical

Center

Chief Investigator: Takeshi Takahashi

Sub Investigator: Masahiro Harada, Toshihiro Sakurai,

Maki Kitada, Shu Yamada, Kohei Karino, Tadashi Era

Nihon University Hospital

Chief Investigator: Ken Nagao

Sub Investigator: Kimio Kikushima, Kazuhiro Watanabe,

Shingo Furuya, Kiyoshi Iida, Mitsunobu Enomoto, Masaaki

Matsumoto, Takeshi Soga, Harumi Hirose, Masakazu

Matsuzaki, Tsutomu Kobari, Koichiro Kazeto, Kei

Nishikawa

Center for Emergency and Critical Care Medicine, Kobe

University Hospital, Emergency and Critical Care

Center, Hyogo College of Medicine Hospital

Chief Investigator: Joji Kotani

Hyogo College of Medicine Hospital

Sub Investigators: Atsunori Hashimoto, Takahiro Ueda, Takaaki Osako, Taihei Yamada, Kenichi Matsuda,

Norichika Yoshie, Hiroyuki Sakata, Sana Okamoto, Toru

Arii, Hideyuki Kijima, Kojiro Miki, Kenichi Fujii, Ken

Kotani, Tadashi Fukunaga, Takahiro Imanaka, Tomotaka

Ando, Hiroto Tamaru

Yamaguchi Prefectural University

Chief Investigator: Tsuyoshi Maekawa.

\section{Authors' Contributions}

All authors participated in the design and coordination of the study and in drafting the article. All authors read and approved the final article.

\section{Acknowledgments}

This clinical trial was required by the Ministry of Health, Welfare, and Labor of Japan to obtain regulatory approval for the Thermogard XP, Start-up Kit, and Quattro/ICY intravascular heat exchange catheters for the indication of therapeutic hypothermia.

\section{Declarations}

Ethics approval and consent to participate

The protocol was approved by the institutional review boards at all participating hospitals.

\section{Consent for publication}

Not applicable in this section.

\section{Availability of data and material}

The protocol was registered on the U.S. National Institute of Health ClinicalTrials.gov website (identifier: NCT01847482).

\section{Author Disclosure Statement}

T.M. was an advisory consultant for and received consultancy and traveling fees from Asahi Kasei ZOLL Medical Co. Ltd. (Japan). K.K., R.T., Y.K., K.N., K.R., T.T., H.Y., S.-I.S., M.H., J.K., and S.E. have received fees from Asahi Kasei ZOLL Medical Co. Ltd. (Japan) for travel and attending steering committee meetings.

\section{Funding Information}

The Thermogard system was supplied to each institution by ZOLL Circulation, Inc. through Asahi Kasei Medical Co. Ltd. (Japan).

\section{References}

Al-Senani FM, Graffagnino C, Grotta JC, et al. A prospective, multicenter pilot study to evaluate the feasibility and safety of using the CoolGard ${ }^{\mathrm{TM}}$ system and $\mathrm{Icy}^{\mathrm{TM}}$ catheter following cardiac arrest. Resuscitation 2004; 62:143-150.

Atkinson RS, Rushman GB, Alfred Lee J. Neurolept anesthesia and the phenothiazine derivatives. In: Synopsis of Anesthesia. Eighth Edition. Atkinson RS, Rushman GB, Alfred Lee J. (eds). Bristol: John Wright \& Sons Ltd., 1977, pp. 289-300.

Bernard S, Buist M, Monteiro O, et al. Induced hypothermia using large volume, ice-cold intravenous fluid in comatose survivors of out-of-hospital cardiac arrest: a preliminary report. Resuscitation 2003;56:9-13.

Bernard SA, Gray T, Buist MD, et al. Treatment of comatose survivors of out-of-hospital cardiac arrest with induced hypothermia. N Engl J Med 2002;346:557-563.

Chamorro C, Borrallo JM, Romera MA, et al. Anesthesia and analgesia protocol during therapeutic hypothermia after cardiac arrest: a systematic review. Anesth Analg 2010;110:1328-1335.

Deye N, Cariou A, Girardie P, et al. on behalf of the ICEREA Study Group: endovascular versus external targeted temperature management for out-of-hospital cardiac arrest patients: a randomized controlled study. Circulation 2015;132:181-193.

Fukuda K. Opioids. In: Miller's Anesthesia. Seventh Edition. Miller RD, Eriksson LI, Fleisher LA, et al. (eds). Philadelphia: Churchill Livingstone, an imprint of Elsevier Inc., 2010, pp. 769-824.

Guyton AC, Hall JE. Body temperature, temperature regulation and fever. In: Text Book of Medical Physiology. Eleventh Edition. Guyton AC, Hall JE (eds). Amsterdam: Elsevier Saunders, 2005, pp. 889-901.

Hoedemaekers CW, Ezzahti M, Gerritsen A, et al. Comparison of cooling methods to induce and maintain normo- and hypothermia in intensive care unit patients: a prospective intervention study. Critical Care 2007;11:R91.

Howes D, Gray SH, Brooks SC, et al. Canadian guidelines for the use of targeted temperature management (therapeutic hypothermia) after cardiac arrest: a joint statement from The Canadian Critical Care Society (CCCS), Canadian Neurocritical Care Society (CNCCS), and the Canadian Critical Care Trials Group (CCCTG). Resuscitation 2016;98:48-63. 
Howes D, Ohley W, Dorian P, et al. Rapid induction of therapeutic hypothermia using convective-immersion surface cooling: safety, efficacy and outcomes. Resuscitation 2010; 81:388-392.

Kaisti KK, Langsjo JW, Aalto S, et al. Effects of sevoflurane, propofol, and adjunct nitrous oxide on regional cerebral blood flow, oxygen consumption, and blood volume in humans. Anesthesiology 2003;99:603-613.

Keller E, Imhof H-G, Gasser S, et al. Endovascular cooling with heat exchange catheters: a new method to induce and maintain hypothermia. Intensive Care Med 2003;29:939-943.

Kirkegaard H, Soreide E, Haas I de, et al. Targeted temperature management for 48 vs 24 hours and neurologic outcome after out-of-hospital cardiac arrest. A randomized clinical trial. JAMA 2017;318:341-350.

Kliegel A, Losert H, Sterz F, et al. Cold simple intravenous infusions preceding special endovascular cooling for faster induction of mild hypothermia after cardiac arrest a feasibility study. Resuscitation 2005;64:347-351.

Maekawa T, Naritomi H, Nozaki K. Clinical application of mild hypothermia in acute brain insults: a review. J Jpn Soc Intensive Care Med 1997;4:199-206.

Maekawa T, Yamashita S, Nagao S, et al.; on behalf of the BHYPO Study Group. Prolonged mild therapeutic hypothermia versus fever control with tight monitoring and slow re-warming in patients with severe traumatic brain injury: a randomized controlled trial. J Neurotrauma 2015;32:422 429.

Matthews JN, Altman DG, Campbell MJ, et al. Analysis of serial measurements in medical research. BMJ 1990;300: 230-235.

Morrison LJ, Deakin CD. Advanced Life Support Chapter Collaborators, Part 8: advanced life support: 2010 international consensus on cardiopulmonary resuscitation and emergency cardiovascular care science with treatment recommendations. Circulation 2010;122 (16 Suppl 2):S345-S421.

Naguib M, Lien CA. Pharmacology of muscle relaxants and their antagonists. In: Miller's Anesthesia. Seventh Edition. Miller RD, Eriksson LI, Fleisher LA, et al. (eds). Philadelphia: Churchill Livingstone, an imprint of Elsevier Inc., 2010, pp. 859-911.

Nielsen N, Wetterslev J, Cronberg T, et al. Targeted temperature management at $33^{\circ} \mathrm{C}$ versus $36^{\circ} \mathrm{C}$ after cardiac arrest. N Engl J Med 2013;369:2197-2206.

Ogawa Y, Iwasaki K, Aoki K, et al. The effects of midazolam and propofol sedation on dynamic cerebral autoregulation. Anesth Analg 2010;111:1279-1284.

Oshima T, Karasawa F, Satoh T. Effects of propofol on cerebral blood flow and the metabolic rate of oxygen in humans. Acta Anaesthesiol Scand 2002;46:831-835.

Patel PM, Drummond JC. Cerebral physiology and the effects of anesthetic drugs. In: Miller's Anesthesia. Seventh Edition. Miller RD, Eriksson LI, Fleisher LA, et al. (eds). Philadel- phia: Churchill Livingstone, an imprint of Elsevier Inc., 2010, pp. 305-339.

Polderman KH, Herold I. Therapeutic hypothermia and controlled normothermia in the intensive care unit: practical considerations, side effects, and cooling methods. Crit Care Med 2009;37:1101-1120.

Polderman KH, Noc M, Beishuizen A, et al. Ultrarapid induction of hypothermia using continuous automated peritoneal lavage with ice-cold fluids: final results of the cooling for cardiac arrest or acute ST-elevation myocardial infarction trial. Crit Care Med 2015;43:2191-2201.

Reves JG, Glass PSA, Lubarsky DA, et al. Intravenous anesthetics. In: Miller's Anesthesia. Seventh Edition. Miller RD, Eriksson LI, Fleisher LA, et al. (eds). Philadelphia: Churchill Livingstone, an imprint of Elsevier Inc., 2010, pp. 719-768.

Safar P. Resuscitation after brain ischemia. In: Brain Failure and Resuscitation. Grenvik A, Safar P (eds). New York: Churchill Livingstone, 1981, pp. 155-184.

Sakamoto T, Morimura N, Nagao K, et al. on behalf of SAVE-J Study Group: extracorporeal cardiopulmonary resuscitation versus conventional cardiopulmonary resuscitation in adults with out-of-hospital cardiac arrest: A prospective observational study. Resuscitation 2014;85:762-768.

Salciccioli JD, Cocchi MN, Rittenberger JC, et al. Continuous neuromuscular blockade is associated with decreased mortality in post-cardiac arrest patients. Resuscitation 2013;84: $1728-1733$.

Sari A, Okuda Y, Takeshita H. The effects of thalamonal on cerebral circulation and oxygen consumption in man. Br J Anaesth 1972;44:330-334.

Sawyer KN, Mooney M, Norris G, et al. COOL-ARREST: Results from a pilot multicenter, prospective, single arm observational trial to assess intravascular temperature management in the treatment of cardiac arrest. Ther Hypothermia Temp Manag 2019;9:56-62.

Schock RB, Janata A, Peacock WF, et al. Time to cooling is associated with resuscitation outcomes. Ther Hypothermia Temp Manag 2018;6:208-216.

The Hypothermia After Cardiac Arrest Study Group. Mild therapeutic hypothermia to improve the neurological outcome after cardiac arrest. N Engl J Med 2002;346:549-556.

Tømte O, Degni T, Mangschau A, et al. A comparison of intravascular and surface cooling techniques in comatose cardiac arrest survivors. Crit Care Med 2011;39:443-449.

Address correspondence to: Tsuyoshi Maekawa, MD, PhD Yamaguchi Prefectural University 3-2-1 Sakurabatake Yamaguchi-shi, Yamaguchi 753-8502 Japan

E-mail: tmaekawa@yamaguchi-pu.ac.jp 